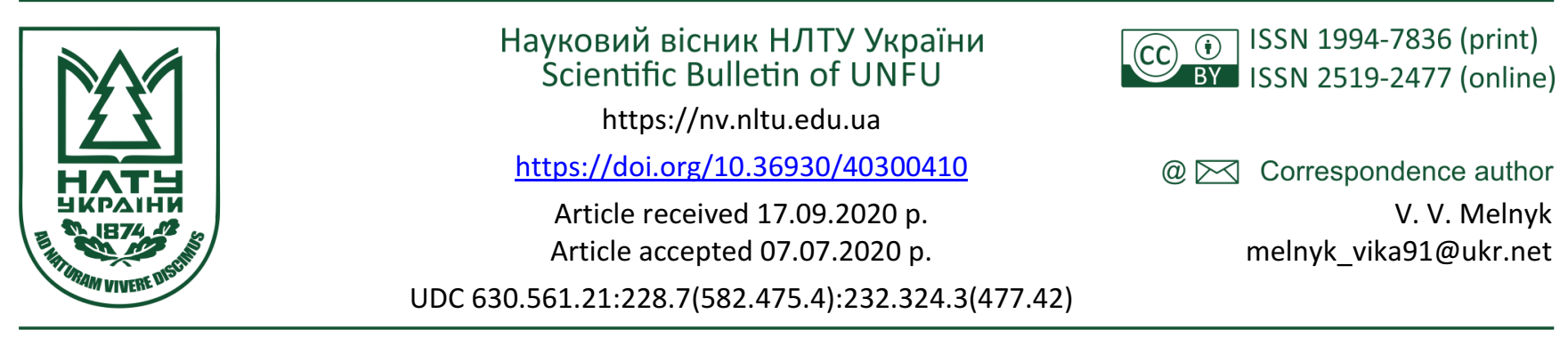

В. П. Краснов ${ }^{1}$, О. В. Жуковський², О. В. Зборовська², В. В. Мельник ${ }^{1}$

${ }^{1}$ Державний університет "Житомирська політехніка", м. Житомир, Украӥна

${ }^{2}$ Поліський філіал УкрНДІЛГА ім. Г. М. Височького, с. Довжик, Україна

\title{
РАДІАЛЬНИЙ ПРИРІСТ СОСНОВИХ НАСАДЖЕНЬ, СТВОРЕНИХ З РІЗНОЮ ГУСТОТОЮ В ЖИТОМИРСЬКОМУ ПОЛІССІ
}

\begin{abstract}
Досліджено насадження сосни звичайної (Pinus sylvestris L.) в Житомирському Поліссі на стаціонарному досліді № 1 впродовж 2010-2012 років. Проаналізовано величини середнього, максимального та мінімального радіальних приростів сосни звичайної, а також динаміку поточного радіального приросту. Виявлено, що середня величина радіального приросту в насадженнях коливається в діапазоні 2,49-3,70 мм. На варіантах досліду в насадженнях з початковою густотою 4000,2000 і 1000 шт. га $^{-1}$ відмінність середнього радіального приросту відсутня або знаходиться в діапазоні 1-8\%. Величини максимальних приростів у соснових насадженнях досліду коливаються в діапазоні 5,34-7,32 мм, а величини мінімальних - 0,831,36 мм. Продемонстровано динаміку радіальних поточних приростів й різницю між ними. Встановлено, що достовірна різниця коливається в діапазоні 3-34 \%. Вона спостерігається між насадженнями з початковою густотою 4000 і 2000 шт. га ${ }^{-1}$ у період з 1982-1984 до 1994-1997 pp., між сосняками з початковою кількістю дерев на одиниці площі 2000 і 1000 шт. га ${ }^{-1}$ у період з 1982-1985 до 1999-2001 pp., і між насадженнями з початковою густотою 4000 і 1000 шт. га ${ }^{-1}$ у період з 1982-1984 до 2006-2010 рр. Зроблено висновки про те, що величина середнього радіального приросту і формування поточного радіального приросту залежать від початкової густоти, а величини максимального та мінімального поточного радіального приростів не залежать від початкової густоти насадження.
\end{abstract}

Ключові слова: лісові культури; сосна звичайна; динаміка радіального приросту; коефіцієнт синхронності; рівень синхронності; густота деревостану.

\section{Вступ}

У Житомирському Поліссі України деревостани сосни звичайної займають близько $59 \%$ вкритих лісовою рослинністю площ [9]. Під час їх створення та вирощування виникають численні питання, одним з яких $є$ початкова густота соснових деревостанів. Планування початкової густоти та підтримання ії на певному рівні в майбутньому за допомогою лісокультурних і лісогосподарських заходів дає змогу вирощувати соснові деревостани певного цільового призначення з оптимальними лісівничо-таксаційними показниками $[6,15,21]$. $A \kappa-$ туальність дослідження полягає в розширенні знань стосовно продуктивності та стану соснових насаджень, які створюються з різною початковою кількістю дерев на площі.

Об'єкт дослідження - 40-річні соснові насадження, що ростуть у свіжому суборі Житомирського Полісся.

Предмет дослідження - динаміка радіального приросту 40-річних соснових насаджень.

Мета дослідження - встановлення закономірностей зміни радіального приросту соснових насаджень з різною початковою густотою в Житомирському Поліссі.

Для досягнення зазначеної мети потрібно виконати такі основні завдання дослідження: полягало у визначенні впливу початкової густоти на формування радіальних приростів сосни звичайної в умовах Житомирського Полісся.

Наукова новизна отриманих результатів дослідження полягає в тому, що вперше проаналізовано радіальний приріст сосни звичайної, створеної з різною початковою кількістю дерев на площі, задля виявлення залежності продуктивності насаджень від початкової густоти. Результати дослідження можуть бути використані в практиці вирощування лісових культур лісовими підприємствами регіону.

Матеріали та методи дослідження. Дослідження здійснювали на стаціонарному досліді № 1 у Кримокському лісництві ДП "Радомишльське лісомисливське господарство" Житомирська область, Україна (північна широта - 50²3 $59.02^{\prime \prime}$, східна довгота -

Інформація про авторів:

Краснов Володимир Павлович, д-р с.-г. наук, професор, кафедра екологіï. Email: volodkrasnov@gmail.com; https://orcid.org/0000-0003-1779-9544

Жуковський Олег Валерійович, наук. співробітник, лабораторія лісівництва. Email: zh_oleh2183@ukr.net; https://orcid.org/0000-0003-3351-9856

3боровська Ольга Володимирівна, канд. с.-г. наук, ст. наук. співробітник, відділ радіаційної екології лісу. Email: olga.zborovska@ukr.net; https://orcid.org/0000-0003-1649-0297

Мельник Вікторія Вікторівна, асистент, кафедра екологіï. Email: melnyk_vika91@ukr.net; https://orcid.org/0000-0002-3551-5085

Цитування за ДСтУ: Краснов В. П., Жуковський О. В., Зборовська О. В., Мельник В. В. Радіальний приріст соснових насаджень, створених з різною густотою в Житомирському Поліссі. Науковий вісник НЛтУ України. 2020, т. 30, № 4. С. 57-61.

Citation APA: Krasnov, V. P., O. V. Zhukovskyi, O. V. Zborovska, Melnyk, V. V. (2020). Radial growth of pine plantations created with different densities in Zhytomyr Polissya. Scientific Bulletin of UNFU, 30(4), 57-61. https://doi.org/10.36930/40300410 
29²5'21.01"). Дослідний об'єкт закладено 1976 р. у виробничих соснових культурах, які створені у 1972 р. (садінням рядами у борозни, вручну). Рельєф - рівнинний, грунт - дерново-слабо-опідзолений піщаний, тип лісорослинних умов - свіжий субір.

Культури сосни звичайної на дослідному об'єкті за густотою розділені на 3 варіанти: секції № $1 \ldots 4$ 4000 шт. га $^{-1}$, секції № 5...8 - 2000 шт. га $^{-1}$ і секції № $9 \ldots 12-1000$ шт. га $^{-1}$, а за агротехнічними заходами вони розділені на 4 варіанти: використання гербіцидів (зеозин 2 рази в дозі 7,5 кг·га ${ }^{-1}$ ) на секціях № 1 , 5 і 9; використання гербіцидів (зеозин 2 рази в дозі 7,5 кг·га $\left.{ }^{1}\right)$ та мінеральних добрив (гранульована аміачна селітра 1 раз в дозі 200 кг·га ${ }^{-1}$ ) на секціях № 2, 6 і 10; використання мінеральних добрив (гранульована аміачна селітра 1 раз в дозі 200 кг·га ${ }^{-1}$ ) на секціях № 3, 7 і 11; проведення механізованого догляду на секціях 4, 8 і 12 [4].

Пробні площі у соснових культурах закладали відповідно до загальноприйнятого стандарту 02.02-37-476:2006 [14]. На закладених пробних площах здійснено відбір 25 кернів деревини. Відбір кернів проводили на висоті 1,3 м за допомогою бура Преслера $[1,3]$. Величини радіальних приростів вимірювали за допомогою мікрометра Corim Maxi 3 точністю 0,01 мм [5, 7]. Далі за допомогою методу перехресного датування проведено вибракування ненадійних рядів та присвоєння кожному радіальному приросту дати формування [16, 22]. Надійність отриманих серій рядів радіального приросту (хронологій) оцінено з використанням загальноприйнятої методики за допомогою вирахування expressed population signal (EPS): $\mathrm{EPS}=\mathrm{trbt} /(\mathrm{trbt}+(1-\mathrm{rbt}))$, де: $\mathrm{t}-$ кількість дерев; rbt - ceредня величина коефіцієнта кореляції між окремими серії (за значення EPS $\geq 0,85$ хронологія вважається достатньо представницькою) [16]. Для виявлення подібності між хронологіями проведено вирахування коефіцієнтів синхронності (S) і за цим встановлювали рівні синхронності. Коефіцієнт синхронності вираховували за формулою: $\mathrm{S}=(\mathrm{n}+\mathrm{n}-1) \cdot 100 \%$, де $\mathrm{n}+-$ кількість співпадаючих по напрямку зміни річних відрізків двох хронологій, $\mathrm{n}-$ тривалість інтервалу порівнюваних хронологій. Рівень синхронності встановлювали за такою шкалою: відсутній (величина коефіцієнта синхронності - 45-56 \%), низький (57-67 \%), середній (68-78 \%), високий (79-89\%) і дуже високий $(90-100 \%)$ [3, 16].

Встановлення величини середнього, максимального, мінімального стандартних відхилень та коефіцієнта варіації радіальних приростів, а також достовірної різниці середніх величин радіальних приростів проводили за допомогою функцій "проста статистика" та "однофакторного дисперсійного аналізу" в програмі Microsoft Office Excel.

Аналіз останніх досліджень та публікацій. За останні 50 років на Поліссі України відбувається інтенсивне ведення лісового господарства, спрямоване на отримання продуктивних лісових насаджень найпоширенішої деревної породи регіону - сосни звичайної. Досить оперативно й об'єктивно охарактеризувати стан лісових насаджень можна, використовуючи такий показник, як - радіальний приріст, який залежить від кліматичних факторів, лісорослинних умов, густоти деревостану, а також і антропогенних факторів. Вивчення радіального приросту окремих дерев i деревостанів здійснюють дендрохронологічним методом. Так, можна вивчати залежність структури, продуктивності та стану соснових насаджень від початкової густоти $[1,3,16$, 22]. В різні періоди в Україні, з використанням дендрохронологічного методу вивчали: вплив полютантів та проникаючої радіації на ріст соснових деревостанів $[12,13,17]$; формування сосняків на грунтах з різними материнськими породами та у різних лісорослинних умовах $[8,20]$ тощо. 3 використанням цього ж методу, досліджували також: динаміку радіального приросту сосняків [18]; вплив кліматичних умов, лісокористування (підсочування) та підліску на формування деревостанів сосни звичайної і інших деревних порід [2, 10, 11, 19].

Однак, незважаючи на набутий науково-практичний досвід, питання початкової густоти соснових культур для вирощування стійких і високопродуктивних деревостанів певного цільового призначення й досі залишається не вирішеним.

\section{Результати дослідження та їх обговорення}

Дендрохронологічний метод дає змогу проаналізувати не тільки просторову динаміку росту соснових деревостанів, а й динаміку окремих таксаційних параметрів у часі. Для цього в усіх дослідних насадженнях відібрано, виміряно та створено ряди радіальних приростів. За вираженим сигналом популяції (EPS) вирахувано їх надійність. Так, для соснових насаджень 3 різною кількістю дерев на площі на стаціонарного досліді № $1 \mathrm{EPS}=0,99 \geq 0,85$, що вказує на високу надійність усіх рядів радіальних приростів і вибірки, є достатньо представницькими.

Для встановлення зв'язку між рядами радіальних приростів вирахувано коефіцієнт синхронності. Так, на варіанті з використанням гербіцидів рівень синхронності рядів радіальних приростів між насадженнями 3 початковою густотою 4000, 2000 і 1000 шт. га ${ }^{-1} \epsilon$ високим і знаходиться у межах 79-85\%. На варіанті з використанням гербіцидів i мінеральних добрив рівень синхронності рядів радіальних приростів між насадженнями 3 початковою густотою 4000 і 2000 шт. га $^{-1}$ та 2000 i 1000 шт. га ${ }^{-1}$ є низьким (64-67 \%), а між насадженнями $з$ початковою густотою 4000 і 1000 шт. га ${ }^{-1}$ середнім $(73 \%)$. На варіанті з використанням хімічних елементів живлення рівень синхронності рядів радіальних приростів між насадженнями з початковою густотою 4000 і 1000 шт. га ${ }^{-1}$ та 2000 і 1000 шт. га $^{-1} \epsilon$ середнім (по $73 \%$ ), між насадженнями 3 початковою густотою 4000 і 2000 шт. га $^{-1}-$ низьким $(67 \%)$. На варіанті 3 проведенням механізованого розпушування грунту рівень синхронності рядів радіальних приростів між насадженнями 3 початковою густотою 4000, 2000 i 1000 шт. га $^{-1} \epsilon$ високим (88 \%) і середнім (70-76 \%). Отже, за коефіцієнтом синхронності на дослідному об'єкті № 1 рівень синхронності між окремими сосновими культурами у межах варіантів коливається від низького до середнього або від середнього до високого.

Середнє значення річного кільця (радіального приросту) на базовому дослід № 1 знаходиться у діапазоні $2,49 . .3,70$ мм (таблиця). На варіанті з використанням гербіцидів різниця середніх значень радіального приросту між насадженнями з початковою густотою 4000, 2000 і 1000 шт. га ${ }^{-1}$ відсутня. На варіантах $з$ використанням гербіцидів і мінеральних добрив відмінність середніх значень радіального приросту між окремими насадженнями $є$ найбільшою. У насадженнях з початковою кількість дерев на одиниці площі 4000 і 1000 шт. га $^{-1}$ во- 
на становить $8 \%$. Водночас різниця середніх величин радіального приросту між насадженнями 3 початковою густотою 4000 і 2000 шт. га $^{-1}$ та 2000 і 1000 шт. $\cdot$ га $^{-1}$ становить тільки 1-3\%. На варіанті з використанням хімічних елементів живлення відмінність середніх величин радіального приросту між сосняками з початковою гус- тотою 2000 і 1000 шт. $\cdot$ га $^{-1}$ та 4000 і 1000 шт. $\cdot$ га $^{-1} \epsilon$ 5$7 \%$. На варіанті з проведенням механізованого розпушування грунту спостерігається невисока різниця середніх значень радіального приросту між насадженнями 3 початковою густотою 4000 і 2000 шт. га $^{-1}$ та 4000 i 1000 шт. га $^{-1}$, де вона становить по $3 \%$.

Таблиця. Характеристика середніх значень величин річних кілець у соснових культурах з різною густотою (стаціонарний дослід № 1)

\begin{tabular}{|c|c|c|c|c|c|c|c|}
\hline \multirow{2}{*}{$\begin{array}{c}\text { № } \\
\text { секції }\end{array}$} & \multirow{2}{*}{ 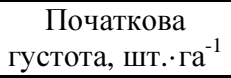 } & \multirow{2}{*}{$\begin{array}{l}\text { Кількість } \\
\text { кернів, шт. }\end{array}$} & \multicolumn{3}{|c|}{ Ширина річних кілець, мм } & \multirow{2}{*}{$\begin{array}{c}\text { Стандартне } \\
\text { відхилення }(\sigma), \text { мм }\end{array}$} & \multirow{2}{*}{$\begin{array}{c}\text { Коефіцієнт } \\
\text { варіації }(V), \%\end{array}$} \\
\hline & & & $M \pm m$ & Max & Min & & \\
\hline \multicolumn{8}{|c|}{ Варіант з використанням гербіцидів } \\
\hline 1 & 4000 & 17 & $2,87^{ \pm 0,25}$ & 6,14 & 1,02 & 1,47 & 51 \\
\hline 5 & 2000 & 17 & $3,05^{ \pm 0,29}$ & 5,77 & 0,95 & 1,66 & 55 \\
\hline 9 & 1000 & 19 & $3,16^{ \pm 0,34}$ & 7,07 & 0,88 & 2,00 & 63 \\
\hline \multicolumn{8}{|c|}{ Варіант з використанням гербіцидів і мінеральних добрив } \\
\hline 2 & 4000 & 16 & $2,49^{ \pm 0,22}$ & 5,34 & 1,09 & 1,27 & 51 \\
\hline 6 & 2000 & 21 & $2,90^{ \pm 0,28}$ & 6,61 & 1,01 & 1,63 & 56 \\
\hline 10 & 1000 & 24 & $3,67^{ \pm 0,32}$ & 6,71 & 1,10 & 1,85 & 50 \\
\hline \multicolumn{8}{|c|}{ Варіант з використанням мінеральних добрив } \\
\hline 3 & 4000 & 20 & $2,53^{ \pm 0,23}$ & 5,37 & 0,91 & 1,36 & 54 \\
\hline 7 & 2000 & 17 & $2,70^{ \pm 0,24}$ & 5,93 & 1,08 & 1,42 & 53 \\
\hline 11 & 1000 & 24 & $3,70^{ \pm 0,30}$ & 6,89 & 1,13 & 1,78 & 48 \\
\hline \multicolumn{8}{|c|}{ Варіант з проведенням механізованого догляду } \\
\hline 4 & 4000 & 18 & $2,51^{ \pm 0,27}$ & 5,93 & 0,83 & 1,55 & 62 \\
\hline 8 & 2000 & 17 & $3,14^{ \pm 0,32}$ & 7,32 & 0,95 & 1,85 & 59 \\
\hline 12 & 1000 & 19 & $3,20^{ \pm 0,26}$ & 6,03 & 1,36 & 1,53 & 48 \\
\hline
\end{tabular}

Примітка: Джерело: авторська розробка.

Загалом простежується тенденція, за якої із зменшенням кількості дерев на одиниці площі сосняку середній радіальний приріст збільшується, але відмінність між середніми значеннями є незначною, всього 1$3 \%$ і тільки між дослідними насадженнями на окремих варіантах досліду вона становить 5-8\%. Максимальна величина радіального приросту на базовому досліді № 1 знаходиться у діапазоні 5,34-7,32 мм, а мінімальна - 0,83-1,36 мм, тенденцій залежності від густоти не виявлено. Стандартне відхилення і коефіцієнт варіації наведено у таблиці.

Середні величини радіального приросту показують неповну інформацію про формування цього показника. Оскільки на нього впливають внутрішні та зовнішні фактори, ці впливи часто буваю короткотерміновими. Тому доцільно проаналізувати динаміку величини радіального приросту соснових насаджень за значний період їх формування. У варіанті з використанням гербіцидів у насадженнях з початковою густотою 4000, 2000 i 1000 шт. га $^{-1}$ не виявлено значних відмінностей між рядами радіального приросту (рис., $a$ ). Різниця між ними є 1-7 \%, що вказує на подібність їх формування. Піки найбільших величин радіальних приростів припадають на 1980-1982 pp.

На варіанті з використанням гербіцидів і хімічних елементів живлення виявлено дещо інше формування радіальних приростів (див. рис., б). Достовірну різницю між величинами радіальних приростів виявлено в насадженнях 3 початковою густотою 4000 і 2000 шт.· га ${ }^{1}$ упродовж 1984-1994 pp. і становить 4-11\%, що підтверджується однофакторним дисперсійним аналізом $F_{\phi}=11,93>F_{m(0,95)}=4,35 ;$ у сосняках 3 початковою густотою 1000 і 2000 шт. га ${ }^{-1}$ впродовж 1985-2001 pp. $(3-13 \%)$, де $F_{\phi}=6,74>F_{m(0,95)}=4,15 ;$ у насадженнях 3 початковою густотою 4000 і 1000 шт. га $^{-1}$ впродовж 1982-2006 pp. (3-34\%), де $F_{\phi}=13,33>F_{m(0,95)}=4,15$. Найбільші величини радіального приросту сформувалися в 1979-1982 pp.
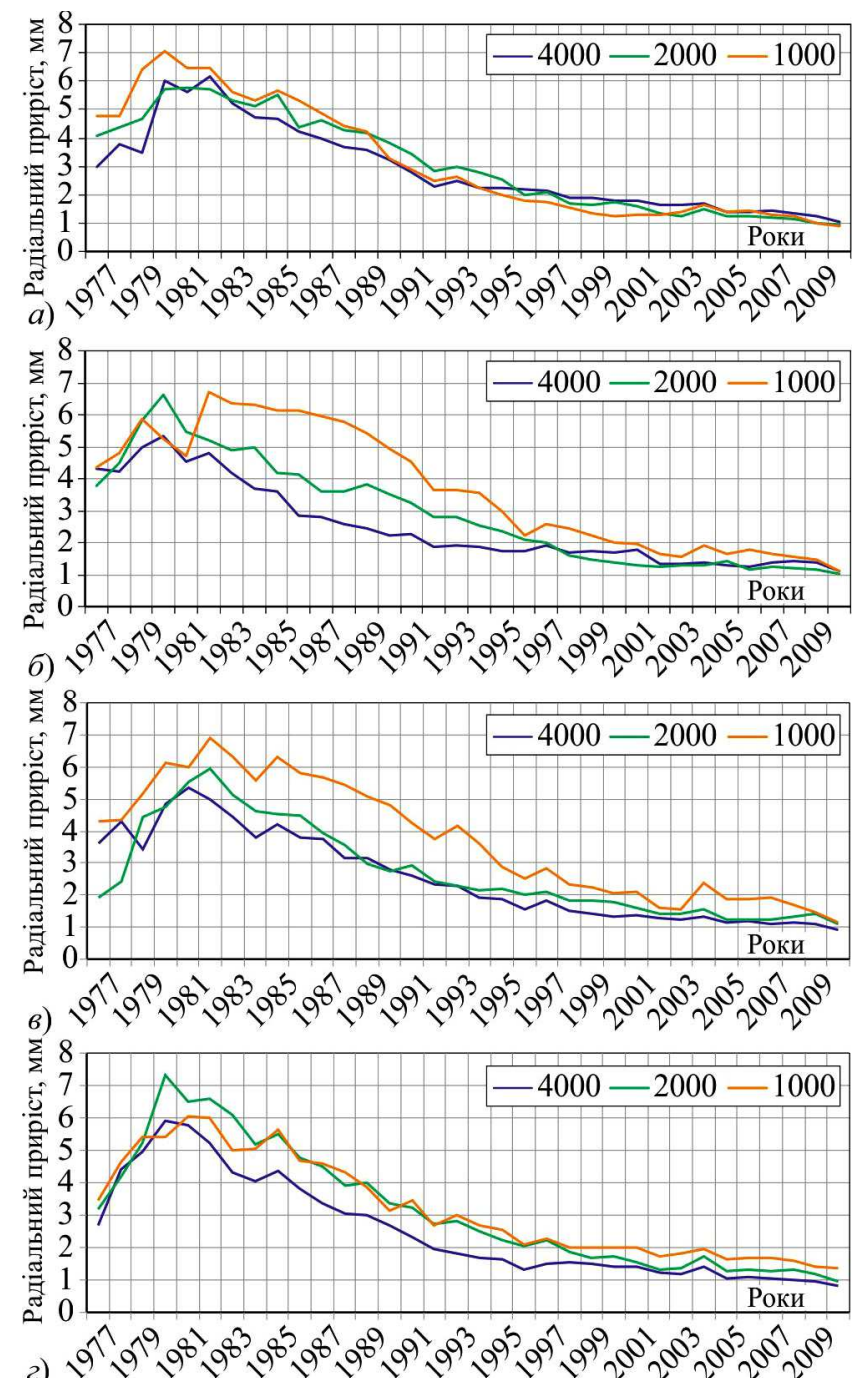

Рисунок. Динаміка радіальних приростів соснових культур 3 різною густотою на варіантах досліду: $a$ ) - використання гербіцидів; б) - використання гербіцидів і мінеральних добрив; в) - 
використання мінеральних добрив; г) - проведення механізованого догляду

Також на цьому варіанті між сосняками з різною початковою кількість дерев на площі не встановлено різниці радіального приросту впродовж 1977-1981 pp. і 2007-2010 pp. На варіанті $з$ використанням хімічних елементів живлення достовірну різницю між величинами радіальних приростів встановлено в насадженнях 3 початковою густотою 4000 i 2000 шт. га $^{-1}$ впродовж 1996-2000 pp. i становить 3-5\%, де $F_{\phi}=15,00>F_{m(0,95)}=5,32 ;$ у насадженнях з початковою густотою 1000 і 2000 шт. га ${ }^{-1}$ впродовж 1982-1999 pp. (4-19\%) i 2004-2007 pp. (9-10\%), де $F_{\phi}=7,39-$ $72,47>F_{m(0,95)}=4,13-18,51 ;$ у насадженнях 3 початковою густотою 4000 і 1000 шт. га $^{-1}$ впродовж 1982 2009 pp. $(5-20 \%)$, де $F_{\phi}=10,01>F_{m(0,95)}=4,02$, а в інші періоди вона відсутня (див. рис., в). Формування найбільшої ширини річного кільця зафіксовано впродовж 1980-1986 pp. Достовірна різниця радіального приросту на варіанті між сосняками з різною густотою відсутня впродовж 1979-1981 pp. На варіанті з проведенням механізованого розпушування грунту достовірна різниця величин радіальних приростів простежується між насадженнями 3 початковою густотою 4000 і 2000 шт. га $^{-1} 1982-1997$ рр. і становить 3-10 \%, де $F_{\phi}=4,30>F_{m(0,95)}=4,17$, між сосняками з початковою густотою 1000 і 2000 шт. га ${ }^{-1}$ впродовж 2000-2010 pp. (3-7 \%), де $F_{\phi}=13,27>F_{m(0,95)}=4,35$ та між насадженнях 3 початковою густотою 4000 і 1000 шт. га $^{-1}$ впродовж 1984-2010 pp. (3-13\%), де $F_{\phi}=6,25>F_{m(0,95)}=4,03$ (рис., г). Найбільші значення радіального приросту відзначено у 1979-1983 рр. Достовірна різниця відсутня між сосняками з різною початковою кількість дерев на площі густотою у період 3 1977 по 1981 pp.

Отже, 3 аналізу абсолютних значень хронологій простежується тенденція, яка свідчить про наявність впливу початкової густоти на формування радіального приросту.

\section{Висновки}

Рівень синхронності рядів радіальних приростів на стаціонарному дослідному об'єкті № 1 між окремими насадженнями у межах варіантів коливається від низького (коефіцієнт синхронності- 64-67 \%) до середнього (73\%) або від середнього (70-76\%) до високого (79-88\%). Середній радіальний приріст збільшується із зменшенням густоти насадження і коливається в діапазоні 2,49-3,70 мм. Різниця між середніми значеннями радіального приросту є незначною, всього 0-3\%, і тільки між насадженнями на окремих варіантах досліду вона становить 5-8 \%.

Аналіз абсолютних значень хронологій свідчить про наявність впливу початкової густоти на формування радіального приросту. Достовірну різницю (3-34 \%) виявлено в окремих сосняках з початковою густотою $4000 \mathrm{i}$ 2000 шт. га $^{-1}$ у період $з$ 1982-1984 до 1994-1997 pp., у насадження з початковою густотою 2000 і 1000 шт.· га ${ }^{1}$ в період з 1982-1985 pр. до 1999-2001 pp. і у насадження 3 початковою густотою 4000 і 1000 шт. га $^{-1}$ у період 3 1982-1984 рр. по 2006-2010 pp.

Сосняки, у свіжих суборах, на стаціонарному досліді мають найбільш оптимальні лісівничо-таксаційні показники за початкової густоти насадження 2000 шт. га $^{-1}$.

\section{References}

1. Anuchin, N. P. (1982). Forest taxation. Moscow: Lesnaia promyshlennost, 552 p. [In Russian].

2. Bijak, Sz. (2013). Sygnał klimatyczny w przyroście radialnym wybranych iglastych gatunków drzew w Leśnym Zakładzie Doświadczalnym Rogów. Leśne Prace Badawcze, 74(2), 101110. https://doi.org/10.2478/frp-2013-0010

3. Bitvinskas, T. (1974). Dendroclimatic studies. Leningrad: Gidrometeoizdat, 170 p. [In Russian].

4. Golovchanskiy, I. N., Belyy, G. D., \& Turchak, F. N. (1976). To develop a set of measures, technologies and recommendations for accelerated growing of wood in plantation-type forests near industrial centers - large consumers of wood. Research Report. Zhytomir: PALOS, 100 p. [In Russian].

5. GRUBE. Fachkatalog. (2010/2011). Bohrkern-Messgerät Corim Maxi. Ausruestungen fuer Wald, Landschaft, Natur und Umwelt, 52, E31 p.

6. Gryb, V. (2015). The impact of economic activities on the state and productivity of artificial pine stands. Scientific Bulletin of UNFU, 25(8), 95-100. https://doi.org/10.15421/40250815

7. Horoshko, M., Myklush, S., Korol, M., \& Vytseha, R. (2006). Modern means of measuring forest inventory. Scientific Bulletin of UNFU, 16(4), 192-200. [In Ukrainian].

8. Khomiuk, P., \& Maksimov, S. (2015). The dynamics of the radial tree stem increment on the selected site conditions within previously drained lands of Rivne region. Scientific Bulletin of UNFU, 25(10), 27-32. https://doi.org/10.15421/40251002

9. Krasnov, V. P., \& Zhukovskiy, O. V. (2013). The structure of the forest fund of Zhytomyr Polissya. Scientific Bulletin of UNFU, 23(6), 27-35. [In Ukrainian].

10. Ludwisiak, Ł., \& Bijak, Sz. (2014). Wpływ podszytu czeremchowego na przyrost radialny sosny pospolitej. Studia $i$ Materiaty CEPL, 40(3), 81-87. [In Polish].

11. Magnuszewski, M., \& Tomusiak, R. (2013). Wpływ żywicowania na przyrost radialny sosny zwyczajnej (Pinus sylvestris L.) na przykładzie drzewostanu w Nadleśnictwie Lidzbark. Leśne Prace Badawcze, 74(3), 273-280. https://doi.org/10.2478/frp-2013-0026

12. Mazepa, V. G., Krynytskyy, H. T., \& Leontjak, H. P. (2009). The results of climate changes and air pollution influence on pine stands radial increment in the conditions of Small Polissya of Ukraine. Scientific Bulletin of UNFU, 19(15), 56-63. [In Ukrainian].

13. Melnyk, V. V., \& Zborovska, O. V. (2018). Radial increment of Scotch pine in Zhytomyr Polissya areas where the thinning of the forest has not been held since the accident at the Chornobyl NPP. Scientific Bulletin of UNFU, 28(8), 65-69. https://doi.org/10.15421/40280813

14. SOU 02.02-37-476. (2006). Forest test plots. Method of laying. Kyiv: Minahropolityky Ukrainy, 32 p. [In Ukrainian].

15. Tarnopilska, O. M. (2008). Peculiarities of growth and forming of artificial stands of Pinus sylvestris L. of different density in the Northern Steppe of Ukraine. Forestry \& Forest Melioration, 112, 62-70. [In Ukrainian].

16. Tishin, D. V. (2015). Dendroecology (methodology of tree-ring analysis). Kazan: Kazan University, 36 p. [In Russian].

17. Voron, V. P., Koval, I. M., \& Leshenko, V. O. (2011). Dynamics of pine radial growth under emissions of Zmiiv fuel-burning power plant. Scientific Bulletin of UNFU, 12(14), 60-66. [In Ukrainian].

18. Zawada, J. (2000). Przyrostowa dynamika sosny w wybranych drzewostanach Krainy Karpackiej i jej konsekwencje hodowlane. Prace Instytutu Badawczego Leśnictwa, 2, 5-22. [In Polish].

19. Zawieja, B., \& Kaźmierczak, K. (2009). The efect of precipitation on the height increments of eight age classes Scots pine (Pinus sylvestris L.). Prace Komisji Nauk Rolniczych i Komisji Nauk leśnych, 105, 7-16. [In Polish].

20. Zborovskaja, O. V., Koval, I. M., \& Zhukovsky, O. V. (2014). Radial growth of Pinus sylvestris L. in stands on morainal and fluvioglacial sand deposits in Ukrainian Polissya. Belgorod State University Scientific Bulletin, 23(29), 25-34. [In Russian].

21. Zhukovskyi, O. (2015). The growth and performance of experimental Scots pine plantations with different density. Scientific 


\section{RADIAL GROWTH OF PINE PLANTATIONS CREATED WITH DIFFERENT DENSITIES} IN ZHYTOMYR POLISSYA

The research was conducted in Zhytomyr Polissya on a stationary experiment N 1 during 2010-2012. The soil and the types of forest site conditions were identified as sod-weakly-podzolic sandy and fresh substrate. The values of medium, maximum and minimum radial growth of pine (Pinus sylvestris L.), as well as the dynamics of current radial growth are analyzed. In the course of research we found that the level of synchronicity between plantations within the variants varied from low to medium (64-76\%) and from medium to high (76-88 \%). The medium size of radial growth in the plantations was revealed to vary in the range of $2.49-3.70 \mathrm{~mm}$. On experimental variants in the plantations with a density of 4000, 2000 and 1000 trees per ha the difference of average radial growth was absent or ranged from $1 \%$ to $8 \%$. The values of maximum growth in the pine plantations of the experiment varied in the range of 5.34-7.32 $\mathrm{mm}$ and the minimum values were 0.83-1.36 mm. The dynamics of radial current growths and the difference between them was demonstrated. It was established that the significant difference varied in the range of 3-34 \%. This was observed among the plantations with a density of 4000 and 2000 trees per ha during the period from 1982-1984 to 1994-1997, among the plantations with a density of 2000 and 1000 trees per ha during the period from 1982-1985 to 1999-2001 and among the plantations with a density of 4000 and 1000 trees per ha during the period from 1982-1984 to 2006-2010. We have concluded that the size of average radial growth and the formation of current radial growth depend on the initial density, whereas maximum and minimum values of current radial growths do not depend on the initial crop density.

Keywords: plantations; Pinus sylvestris L.; dynamics of radial growth; synchronicity coefficient; synchronicity level; stand density. 